\title{
BIOCATALYSIS IN SPAIN: A FIELD OF SUCCESS AND INNOVATION
}

\author{
Andrés R. Alcántara*, Eduardo García-Junceda, Vicente Gotor, \\ Francisco J. Plou
}

\section{PUBLICADO EN:}

Biocatalysis and Biotransformation, 36:3(2017), 180-183, (DOI: https://doi.org/10.1080/10242422.2017.1420064) 


\title{
BIOCATALYSIS IN SPAIN: A FIELD OF SUCCESS AND INNOVATION
}

\author{
Andrés R. Alcántara*1, Eduardo García-Junceda², Vicente Gotor³, \\ Francisco J. Plou 4
}

\begin{abstract}
1Departamento de Química Orgánica y Farmacéutica, Facultad de Farmacia, Universidad Complutense University de Madrid, Campus de Moncloa, E-28040 Madrid, Spain.

2Departamento de Química Bioorgánica, Instituto de Química Orgánica General, CSIC, Juan de la Cierva 3, 28006 Madrid (Spain).

32Departamento de Química Orgánica e Inorgánica. Facultad de Química. Universidad de Oviedo, Julián Claveria 8, 33008 Oviedo (Spain)

${ }^{4}$ Instituto de Catálisis y Petroleoquímica, CSIC, 28049 Madrid, Spain *Address correspondence to this author. Tel: (+34) 913941820, Fax: (+34) 91-3941822, Email: andalcan@ucm.es.
\end{abstract}


Biocatalysis, the use of native or modified enzymes and/or cells in the preparation of high-value products, ranging from pharmaceuticals and fine chemicals to food and energy, has experimented a tremendous progress in the last decade, driven primarily by what has been named as the 'third wave of biocatalysis' (Bornscheuer et al. 2012; Moore \& Bornscheuer 2014), a collection of tools for protein engineering and design that include bioinformatics, high-throughput screening (HTS) and directed evolution, which have absolutely complemented other older and well-established techniques, such as enzyme immobilization or protein/medium engineering (Reetz 2013; Arroyo et al. 2014; Torrelo et al. 2015). On the other hand, the increasing use of biocatalytic methods has been also promoted by the inherent environmental benefits associated with mild and selective biocatalysts, clearly integrated in the philosophy of Green Chemistry (Patel 2016; Sheldon \& Woodley 2017).

Thus, the work of several Spanish groups in the field of Applied Biocatalysis is presented in this Special Issue of Biocatalysis and Biotransformation, covering many of the different aspects of such a multidisciplinary area. In fact, since the pioneering creation of the Biocatalysis Group inside the Catalysis Institute (lately, Institute of Catalysis and Petroleum Chemistry, ICP), inside the CSIC (Spanish Council for Scientific Research) by Prof. A. Ballesteros in the mid-60s in Madrid (Ballesteros 2012), many groups have been working very actively in this field. This fact can be easily observed in Figure 1, depicting the number of publications generated in Spain (Source: Scopus, search operators: Article Title, Abstract or Keywords including "biocatal*" or "biotransf*" and Authors affiliation "Spain") from mid-70s to nowadays, which has experimented an exponential grow, from 2 articles in 1974 up to 237 in 2016.

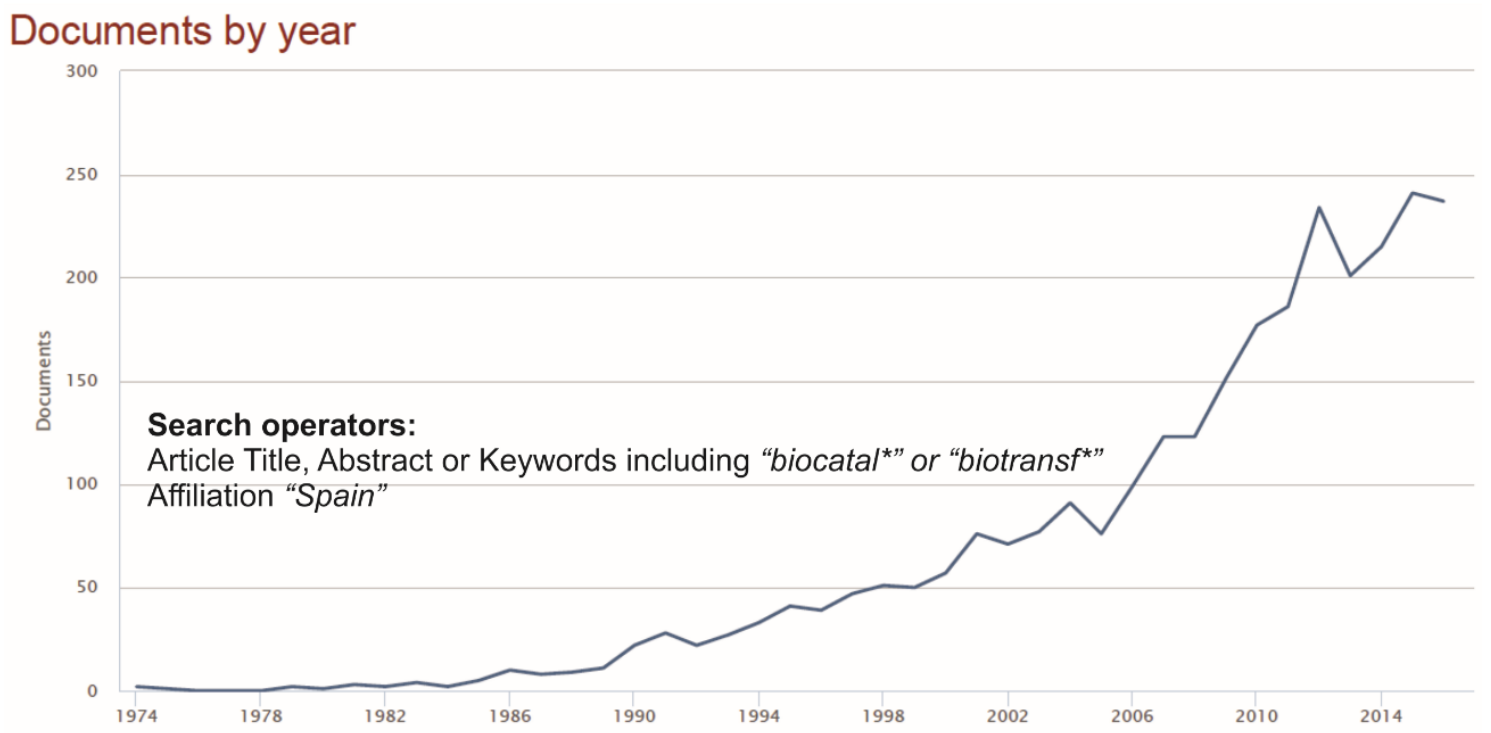

Source: Scopus

Figure 1: Evolution of the scientific production inside the research area of biocatalysis and biotransformations from 1974 up to 2016 (Source: Scopus). 
To really understand this Figure 1, considering the same time period, the evolution of the Spanish scientific publications compared to other "big" European countries is really remarkable, as can be seen in Table 1.

Table 1: Comparative scientific production between Spain and other 4 European countries in the area of biocatalysis and biotransformations between 1974 and 2016 (Source: Scopus)

\begin{tabular}{|c|c|c|c|c|c|}
\hline COUNTRY & $\begin{array}{c}\text { Overall } \\
\text { publications } \\
(1974-2016)\end{array}$ & $\begin{array}{c}\text { Publications } \\
1974\end{array}$ & $\begin{array}{c}\text { Comparative } \\
\text { Spain 1974 }\end{array}$ & $\begin{array}{c}\text { Publications } \\
2016\end{array}$ & $\begin{array}{c}\text { Comparative } \\
\text { Spain 2016 }\end{array}$ \\
\hline SPAIN & 2855 & 2 & ------ & 237 & ------- \\
\hline GERMANY & 7972 & 36 & $5.6 \%$ & 431 & $55.0 \%$ \\
\hline $\begin{array}{c}\text { UNITED } \\
\text { KINGDOM }\end{array}$ & 5433 & 27 & $7.4 \%$ & 221 & $107,2 \%$ \\
\hline FRANCE & 3637 & 19 & $10.5 \%$ & 166 & $142.8 \%$ \\
\hline ITALY & 3094 & 8 & $25 \%$ & 159 & $149.1 \%$ \\
\hline
\end{tabular}

As can be seen from this Table, while in 1974 the Spanish production was only a $5.6 \%$ compared to Germany (the top country in Europe), in 2016 there is a 10-fold increase, reaching a 55\%. Moreover, compared to the other European Countries considered, United Kingdom, France and Italy, in 2016 we can observe how the Spanish scientific production has very clearly overpassed them.

Starting to comment what can be found in the Special Issue: different groups have grown inside the above-mentioned ICP, and the contribution of most of them is present here: thus, González-Pérez \& Alcalde (Group of Directed Enzyme Evolution) describe the directed evolution of versatile peroxidase (VP) from whiterot fungi (Gonzalez-Perez \& Alcalde 2017), while articles from Guisán and coworkers (synthesis of $s n-2$ docosahexaenoyl monoacylglycerol by enzymatic transesterification in a solvent-free system, (Moreno-Perez et al. 2017)); immobilization and stabilization of commercial $\beta-1,4$-endoxylanase by multipoint covalent attachment for production of prebiotics, (Martins de Oliveira et al. 2017); use of immobilized proteases to produce bioactive phosphopeptides from commercial casein hydrolysate, (Rocha-Martin et al. 2017) were remitted from the Enzyme Engineering group. The Applied Biocatalysis Group, directed by F. J. Plou, has contributed with an article on the enzymatic production of fully deacetylated chitooligosaccharides with neuroprotective and anti-inflammatory properties (Santos-Moriano et al. 2017), and Blanco and Roldán, from the group of Molecular Sieves, present their study about the use of additives upon the stability of lipase during non-covalent immobilization (Blanco \& Roldán 2017). Finally, an article from researchers belonging to the groups of Optimization of Biocatalysts and Enzymatic Bioprocess (leaded by R. Fernández-Lafuente), with the cooperation of C. Otero (Group of Biocatalysis and Bioengineering) describes the coating of octyl- 
CALB with ionic polymers to improve stability and decrease enzyme leakage (Fernandez-Lopez et al. 2017);

Also inside CSIC, valuable articles from some other groups from different Institutes are present in this issue; hence, M. J. Martínez, from the Biological Research Centre (CIB, Madrid) reports the production of glucooligosaccharides from different $\beta$ glucans using $\beta$-1,4-endoglucanases from Talaromyces amestolkiae (de Eugenio et al. 2017), while García-Junceda, Bastida and coworkers, from the Institute of General Organic Chemistry (IQOG, Madrid), describe an improved enzymatic peptide synthesis by using biphasic reactors (Bastida et al. 2017).

Another considerable number of contributions to this Special Issue come from Spanish Universities; thus, from Complutense University of Madrid (UCM), where different research groups have been working for many years in this area, we can find review articles from Heras and coworkers (production of $D$-amino acids using hydantoin immobilized on chitin and chitosan, (Aranaz et al. 2017)), Hernáiz et al. (enzymatic synthesis of carbohydrates and glycoconjugates in green solvents, (García et al. 2017)) and Alcántara \& Alcántara (biocatalyzed synthesis of antidiabetic drugs (Alcántara \& Alcántara 2017)). These three articles come from research groups established in the Faculty on Pharmacy. On the other hand, from the Faculty of Biology of UCM, Arroyo and coworkers present a strategy for immobilizing PHB depolymerase on magnetite-based nanoparticles and its use for degrading polyhydroxybutyrate (García-Hidalgo et al. 2017). Also in Madrid, an article leaded by J. Fernández-Lucas, from the European University, report the cloning, expression and biochemical characterization of xanthine and adenine phosphoribosyltransferases from Thermus thermophilus HB8 (Del Arco et al. 2017).

Excellent contributions from other Universities outside Madrid can also be found. So, two contributions are originated from the group of R. Canela at the University of Lleida, one of them reporting the effect of enzymatic treatments on dietary fruit fibre (Canela-Xandri et al. 2017), the other one describing the use of fungi from raw and waste plant materials for the kinetic resolution of aryl and alkyl glycidyl ethers (Dolcet et al. 2017). Another couple of articles come from the University of Santiago de Compostela, under the auspices of J. M. Lema and M. T. Moreira; thus, Arca-Ramos et al. present a review about general application of enzymatic reactors for the removal of recalcitrant compounds in wastewater (Arca-Ramos et al. 2017), whereas Gamallo et al. specifically detail the use of laccase from Myceliophthora thermophila immobilized on fumed silica microparticles for the removal of endocrine disrupting chemicals in a two-enzymes reactor system (Gamallo et al. 2017). Finally, other three remarkable contributions are presented by F. Valero, from Autónoma University of Barcelona, (UAB, immobilization of lipases onto rice husk ash and its further application in the enzymatic production of biodiesel, (Bonet-Ragel et al. 2017)), E. M. Martín del Valle, from University of Salamanca, reviewing levan and levansucrases and their numerous applications in biomedicine and health fields (González-Garcinuño et al. 2017), and V. GotorFernández, from the University of Oviedo, reporting a comprehensive review covering recent developments of stereoselective biotransformations for the 
synthesis of valuable building blocks, pharmaceuticals and biologically active natural products (Albarrán-Velo et al. 2017).

Last but not least, from the private Center for Cooperative Research in Biomaterials- CIC biomaGUNE, located in San Sebastián, Velasco-Lozano and López-Gallego have elaborated an attractive review presenting different available tools to implement immobilized enzymatic cascades into synthetic, analytical, medical and environmental chemistry (Velasco-Lozano \& López-Gallego 2017).

To conclude, the Editors think that readers from Biocatalysis and Biotransformation can extract from this Special Issue a fairly accurate and up-todate vision of the current status of this research field inside Spain. We foresee that the growing expansion of the Spanish contribution will keep on in the following years, as long as more and more scientists from different research fields become involved in the use of biocatalysts in their daily work. 


\section{REFERENCES}

Albarrán-Velo J, González-Martínez D, Gotor-Fernández V. 2017. Stereoselective biocatalysis: A mature technology for the asymmetric synthesis of pharmaceutical building blocks. Biocatal. Biotransform.:1-29.

Alcántara CM, Alcántara AR. 2017. Biocatalyzed synthesis of antidiabetic drugs: A review. Biocatal. Biotransform.:1-35.

Aranaz I, Acosta N, Heras A. 2017. Enzymatic d-p-hydrophenyl glycine synthesis using chitin and chitosan as supports for biocatalyst immobilization. Biocatal. Biotransform.:1-13.

Arca-Ramos A, Eibes G, Feijoo G, Lema JM, Moreira MT. 2017. Enzymatic reactors for the removal of recalcitrant compounds in wastewater. Biocatal. Biotransform.:1-21.

Arroyo M, Acebal C, De La Mata I. 2014. Biocatalysis and biotechnology. Arbor 190.

Ballesteros A. 2012. Biocatalysis: a personal project. In: Sánchez Montero JM, Ortega Ortiz de Apodaca F, Doadrio Villarejo AL. Biocatálisis aplicada a la obtención de fármacos y productos de alto valor añadido: Real Academia Nacional de Farmacia (RANF). pp. 19-60.

Bastida A, Blanco RM, Zárate SG, García-Junceda E, Guisán JM. 2017. Highly improved enzymatic peptide synthesis by using biphasic reactors. Biocatal. Biotransform.:1-8.

Blanco RM, Roldán I. 2017. Two additives to improve stability of immobilized lipase. Biocatal. Biotransform.:1-9.

Bonet-Ragel K, López-Pou L, Tutusaus G, Benaiges MD, Valero F. 2017. Rice husk ash as a potential carrier for the immobilization of lipases applied in the enzymatic production of biodiesel. Biocatal. Biotransform.:1-8.

Bornscheuer UT, Huisman GW, Kazlauskas RJ, Lutz S, Moore JC, Robins K. 2012. Engineering the third wave of biocatalysis. Nature 485:185-194.

Canela-Xandri A, Balcells M, Villorbina G, Cubero MÁ, Canela-Garayoa R. 2017. Effect of enzymatic treatments on dietary fruit fibre properties. Biocatal. Biotransform.:1-8.

de Eugenio LI, Méndez-Líter JA, de los Ríos V, Prieto A, Martínez MJ. 2017. $\beta$-1,4endoglucanases from Talaromyces amestolkiae: Production of glucooligosaccharides from different $\beta$-glucans. Biocatal. Biotransform.:110.

Del Arco J, Martinez M, Donday M, Clemente-Suarez VJ, Fernández-Lucas J. 2017. Cloning, expression and biochemical characterization of xanthine and adenine phosphoribosyltransferases from thermus thermophilus HB8. Biocatal. Biotransform.:1-8.

Dolcet M, Torres M, Canela-Garayoa R. 2017. Raw and waste plant materials as sources of fungi with epoxide hydrolase activity. Application to the kinetic resolution of aryl and alkyl glycidyl ethers. Biocatal. Biotransform.:1-11.

Fernandez-Lopez L, Virgen-OrtÍz JJ, Pedrero SG, Lopez-Carrobles N, Gorines BC, Otero C, Fernandez-Lafuente R. 2017. Optimization of the coating of octylCALB with ionic polymers to improve stability and decrease enzyme leakage. Biocatal. Biotransform.:1-10. 
Gamallo M, Moldes-Diz Y, Eibes G, Feijoo G, Lema JM, Moreira MT. 2017. Sequential reactors for the removal of endocrine disrupting chemicals by laccase immobilized onto fumed silica microparticles. Biocatal. Biotransform.:1-11.

García-Hidalgo J, Acebal C, de la Mata I, Arroyo M. 2017. Developing an efficient strategy for immobilization of PHB depolymerase on magnetite-based nanoparticles for degrading polyhydroxybutyrate in acidic conditions. Biocatal. Biotransform.:1-9.

García C, Hoyos P, Hernáiz MJ. 2017. Enzymatic synthesis of carbohydrates and glycoconjugates using lipases and glycosidases in green solvents. Biocatal. Biotransform.:1-10.

González-Garcinuño Á, Tabernero A, Domínguez Á, Galán MA, Martin del Valle EM. 2017. Levan and levansucrases: Polymer, enzyme, micro-organisms and biomedical applications. Biocatal. Biotransform.:1-12.

Gonzalez-Perez D, Alcalde M. 2017. The making of versatile peroxidase by directed evolution. Biocatal. Biotransform.:1-11.

Martins de Oliveira S, Moreno-Perez S, Romero-Fernández M, Fernandez-Lorente G, Rocha-Martin J, Guisan JM. 2017. Immobilization and stabilization of commercial $\beta$-1,4-endoxylanase Depol ${ }^{\mathrm{TM}} 333 \mathrm{MDP}$ by multipoint covalent attachment for xylan hydrolysis: Production of prebiotics (xylooligosaccharides). Biocatal. Biotransform.:1-10.

Moore JC, Bornscheuer UT. 2014. Editorial overview: Biocatalysis and biotransformation: Riding the third wave of biocatalysis. Curr. Opin. Chem. Biol. 19:5-6.

Moreno-Perez S, Luna P, Señorans J, Rocha-Martin J, Guisan JM, Fernandez-Lorente G. 2017. Enzymatic transesterification in a solvent-free system: synthesis of sn-2 docosahexaenoyl monoacylglycerol. Biocatal. Biotransform.:1-6.

Patel RN. 2016. Green Biocatalysis: John Wiley \& Sons, Inc.

Reetz MT. 2013. Biocatalysis in Organic Chemistry and Biotechnology: Past, Present, and Future. J. Am. Chem. Soc. 135:12480-12496.

Rocha-Martin J, Fernández-Lorente G, Guisan JM. 2017. Sequential hydrolysis of commercial casein hydrolysate by immobilized trypsin and thermolysin to produce bioactive phosphopeptides. Biocatal. Biotransform.:1-16.

Santos-Moriano P, Fernandez-Arrojo L, Mengibar M, Belmonte-Reche E, Peñalver P, Acosta FN, Ballesteros AO, Morales JC, Kidibule P, Fernandez-Lobato M, Plou FJ. 2017. Enzymatic production of fully deacetylated chitooligosaccharides and their neuroprotective and anti-inflammatory properties. Biocatal. Biotransform.:1-11.

Sheldon RA, Woodley JM. 2017. Role of Biocatalysis in Sustainable Chemistry. Chem. Rev.

Torrelo G, Hanefeld U, Hollmann F. 2015. Biocatalysis. Catalysis Letters 145:309345.

Velasco-Lozano S, López-Gallego F. 2017. Wiring step-wise reactions with immobilized multi-enzyme systems. Biocatal. Biotransform.:1-11. 